\title{
LETTER TO THE EDITOR / CARTA AO EDITOR
}

\section{Impact of autocorrelation in the time analysis of HIV mortality coefficients in Brazil}

\section{Impacto da autocorrelação na análise temporal dos coeficientes de mortalidade pelo HIV no Brasil}

Leandro Pereira Garcia', Jefferson Luiz Traebert'

Dear editor,

The idea of the article "HIV/AIDS Mortality in Brazil, 2000-2015: Are there reasons for concern?" of comparing trends of human immunodeficiency virus (HIV) mortality coefficient in Brazil based on data extracted from two important sources - epidemiological bulletins of the Ministry of Health and Global Burden of Disease (GBD) 2015 - is very interesting ${ }^{1}$.

Despite the relevance of the theme and proposal, a methodological issue deserves consideration. In the study, Guimarães et al. ${ }^{1}$ used simple linear regressions to analyze trends and estimated the magnitude of changes through the ratio between angular coefficients produced by these methods. However, the frequent presence of autocorrelation in time series can make simple linear regression a method less suitable for this kind of assessment. This happens because autocorrelation can overestimate the adjusting metrics of the explanatory model, resulting in an inadequate interpretation. ${ }^{2}$ For instance, a model produced by simple linear regression could indicate increasing or decreasing trends in a time series in situations in which such inferences could not be made. Generalized linear models are an alternative in cases of autocorrelation, with Prais-Winsten as the most used. ${ }^{2}$

After analyzing autocorrelation with the same data used by Guimarães et al., ${ }^{1}$ extracted from the epidemiological bulletins of the Ministry of Health, ${ }^{3-5}$ through the DurbinWatson test, we observed its presence in data from Brazil, the Southern and Southeastern regions, and in a series of six other states. Unfortunately, we could not analyze data from the GBD 2015 since the platform removed them after the publication of the GBD 2016.

Therefore, we proceeded with the Prais-Winsten regression in these series to analyze the difference in results produced by both methods. As proposed by Antunes and Cardoso, ${ }^{2}$ we did the logarithmic transformation of the mortality coefficient to reduce heterogeneity of residues variance in the regression. The angular coefficients and standard errors estimated used to calculate the annual percentage variation (APV) allowed us to determine the presence of increasing and decreasing trends or the indeterminacy of the trend, in an intuitive 
way. Thus, positive values indicate an increase in average annual percentage, and negative values, decrease, provided the confidence interval does not contain zero. When that happens, it is not possible to use this method to determine the trend of the series. ${ }^{2}$

The results (Table 1) point to an APV of mortality coefficient in Brazil of around $-2 \%$. Among the regions, the Southeastern shows a decreasing trend, and the Northern

Table 1. Annual percentage variation of human immunodeficiency virus (HIV) mortality coefficient in Brazil, regions, and states, 2000-2015.

\begin{tabular}{|c|c|c|c|c|}
\hline Location & Variation & $\begin{array}{c}95 \% \mathrm{Cl} \\
\text { Max. }\end{array}$ & $\begin{array}{c}95 \% \mathrm{Cl} \\
\text { Min. }\end{array}$ & Trend \\
\hline BRAZIL & -02.12 & -01.13 & -03.10 & Decrease \\
\hline South & -00.19 & 01.62 & -01.96 & Undetermined \\
\hline Paraná & 01.23 & 03.30 & -00.79 & Undetermined \\
\hline Santa Catarina & -02.55 & -00.34 & -04.72 & Decrease \\
\hline Rio Grande do Sul & 00.74 & 03.79 & -02.20 & Undetermined \\
\hline Southeast & -07.08 & -05.30 & -08.83 & Decrease \\
\hline Minas Gerais & -04.35 & -03.24 & -05.44 & Decrease \\
\hline Espírito Santo & 04.35 & 06.98 & 01.78 & Increase \\
\hline Rio de Janeiro & -01.98 & 00.92 & -04.81 & Undetermined \\
\hline São Paulo & -11.14 & -10.05 & -12.21 & Decrease \\
\hline North & 15.14 & 17.73 & 12.60 & Increase \\
\hline Rondônia & 06.35 & 09.37 & 03.41 & Increase \\
\hline Acre & -06.65 & 05.63 & -17.51 & Undetermined \\
\hline Amazonas & 16.71 & 21.76 & 11.86 & Increase \\
\hline Roraima & 02.05 & 10.53 & -05.76 & Undetermined \\
\hline Pará & 17.33 & 19.91 & 14.80 & Increase \\
\hline Amapá & 25.08 & 59.13 & -01.67 & Undetermined \\
\hline Tocantins & 13.38 & 18.22 & 08.74 & Increase \\
\hline Northeast & 08.06 & 08.83 & 07.30 & Increase \\
\hline Maranhão & 17.84 & 20.27 & 15.45 & Increase \\
\hline Piauí & 14.05 & 16.64 & 11.51 & Increase \\
\hline Ceará & 05.49 & 08.69 & 02.39 & Increase \\
\hline Rio Grande do Norte & 12.98 & 24.90 & 02.19 & Increase \\
\hline Paraíba & 08.68 & 13.62 & 03.95 & Increase \\
\hline Pernambuco & 04.09 & 05.69 & 02.50 & Increase \\
\hline Alagoas & 17.03 & 24.56 & 09.95 & Increase \\
\hline Sergipe & 11.30 & 16.36 & 06.45 & Increase \\
\hline Bahia & 05.62 & 06.52 & 04.72 & Increase \\
\hline Midwest & -00.13 & 01.17 & -01.42 & Undetermined \\
\hline Mato Grosso do Sul & -00.45 & 02.99 & -03.80 & Undetermined \\
\hline Mato Grosso & 02.86 & 06.72 & -00.86 & Undetermined \\
\hline Goiás & 02.12 & 04.38 & -00.07 & Undetermined \\
\hline Distrito Federal & -06.10 & -03.06 & -09.04 & Decrease \\
\hline
\end{tabular}

$95 \% \mathrm{Cl}$ : confidence interval of $95 \%$. 
and Northeastern, an increasing trend. It was not possible to determine the trends in the Midwestern and Southern regions, contrary to the findings of Guimarães et al. ${ }^{1}$

Among the 26 states and the Federal District, Guimarães et al. ${ }^{1}$ found decreasing trends of mortality coefficient in six states, with the highest reduction in São Paulo and the lowest in Goiás. ${ }^{1}$ The other states presented no decrease or showed a coefficient increase, with Amapá as the most expressive case.

APV results, however, indicate a decrease in only four states, with São Paulo as the most prominent and Santa Catarina, the least. Fourteen states showed an increasing trend, with Maranhão as the most significant and Pernambuco, the least. Lastly, it was not possible to determine the trends in Goiás, Amapá, and other seven states.

Therefore, as previously mentioned, the use of simple linear regressions can make undetermined trends in time series with autocorrelation to be inaccurately interpreted as increasing or decreasing trends. Methods that adjust autocorrelation in time analysis allows better interpretation of and intervention in health phenomena.

\section{REFERENCES}

1. Guimarães MDC, Carneiro M, Abreu DMX de, França EB. Mortalidade por HIV/Aids no Brasil, 2000-2015: motivos para preocupação? Rev Bras Epidemiol. 2017; 20(Supl. 1): 182-90. http://dx.doi. org/10.1590/1980-5497201700050015

2. Antunes JLF, Cardoso MRA. Uso da análise de séries temporais em estudos epidemiológicos. Epidemiol Serv Saúde. 2015; 24(3): 565-76. http:/ / dx.doi.org/10.5123/ S1679-49742015000300024
- Brasil. Boletim Epidemiológico HIV/AIDS - 2012. Brasília; 2012.

4. Brasil. Boletim Epidemiológico HIV/AIDS - 2015. Brasília; 2015.

5 Brasil. Boletim Epidemiológico HIV/AIDS - 2016. Brasília; 2016. 